\title{
Ablation of Cardiac Accessory Pathway
}

National Cancer Institute

\section{Source}

National Cancer Institute. Ablation of Cardiac Accessory Pathway. NCI Thesaurus. Code C99907.

An invasive therapeutic procedure to destroy tissue in an accessory pathways in the atrioventricular conduction system that contributes to arrhythmia. (ACC) 